\title{
PENGELOLAAN LUBUK LARANGAN SEBAGAI BENTUK KEARIFAN LOKAL DI SUNGAI BATANG JUJUHAN KABUPATEN BUNGO PROVINSI JAMBI
}

\author{
Sairun $^{1}$, Syafrialdi ${ }^{2}$, Djunaidi $^{2}$ \\ ${ }^{1}$ Alumni Program Studi Pemanfaatan Sumberdaya Perikan Fakultas Perikanan \\ ${ }^{2}$ Dosen Program Studi Pemanfaatan Sumberdaya Perikan Fakultas Perikanan \\ Universitas Muara Bungo
}

\begin{abstract}
ABSTRAK
Latar Belakang Perairan Sungai Batang Jujuhan merupakan salah satu sungai utama di Kabupaten Bungo dan merupakan bentuk perairan yang terbuka dan bermuara di sungai Batang Hari. Hasil observasi dilapangan bahwa bagi masyarakat petani nelayan sungai dimanfaatkan untuk usaha penangkapan ikan, budidaya ikan dan sebagian masyarakat digunakan untuk mandi.

Tujuan penelitian adalah untuk mengetahui bagaimana bentuk pengelolaan lubuk larangan sebagai bentuk kearifan lokal di Sungai Batang Jujuhan Kabupaten Bungo.

Metode Deskriptif kualitatif, yaitu untuk memberikan gambaran dan penjelasan secara faktual dan akurat mengenai fakta - fakta dan gejala yang ada di lokasi penelitian, Eksperimen, yaitu melakukan survei, pengambilan data dan pengamatan langsung di lapangan dengan menggunakan data kuisioner atau wawancara langsung dengan responden. Sedangkan data sekunder meliputi inventarisasi kondisi sosial, ekonomi, lingkungan dan budaya masyarakat di kawasan lubuk larangan

Hasil penelitian menyatakan bahwa bentuk - bentuk kearifan lokal masyarakat Dusun Rantau Panjang, Dusun Pulau Batu dan Dusun Aur Gading dalam upaya mengelola lubuk larangan Hugo, Pulau Batu dan lubuk larangan Beringin Jaya terdiri dari : 1) Merencanakan pembentukan lubuk larangan melalui musyawarah dalam upaya menyelamatkan lingkungan perairan sungai, 2) Terbentuknya aturan - aturan dan sanksi bagi lubuk larangan Hugo dan aturan - aturan saja tidak ada sanksi bagi lubuk larangan Pulau Batu dan Beringin Jaya,3) Masyarakat Dusun Rantau Panjang, Dusun Pulau Batu dan Dusun Aur Gading mempunyai kepercayaan bahwa yang mengambil ikan dilubuk larangan akan meninggal, 4) Dapat mengubah prilaku masyarakat kearah yang lebih posistif dari aspek ekologi dan sosial, seperti : Mengunakan alat panen yang ramah lingkungan seperti lukah, jala, jaring dll, Melarang menangkap ikan di sepanjang lubuk larangan, Memelihara dan memanfaatkan lubuk sebagai tempat berkembangbiaknya ikan - ikan.
\end{abstract}

Kata Kunci : Kearifan Lokal, Deskriptif kualitatif, Lubuk Larangan

\section{PENDAHULUAN}

Undang - undang Nomor 32 Tahun

2009 tentang perlindungan dan pengelolaan

lingkungan hidup pasal 1 ayat 30 menjelaskan tentang kearifan lokal yaitu nilai - nilai luhur yang berlaku dalam masyarakat antara lain melindungi dan mengelola lingkungan hidup secara lestari dan ayat 31 menjelaskan tentang masyarakat hukum adat yaitu kelompok 
SEMAH : Journal Pengelolaan Sumberdaya Perairan VOL. 3 No. 1

April 2019

masyarakat yang secara turun - temurun bermukim di wilayah geografis tertentu karena adanya ikatan pada asal - usul leluhur, adanya hubungan yang kuat dengan lingkungan hidup, serta, adanya sistem nilai yang menentukan pranata ekonomi, politik, sosial dan hukum.

Lubuk Larangan merupakan suatu daerah tertentu di sungai yang diberi batasan oleh masyarakat untuk tidak boleh diganggu dan diambil ikannya. Adanya lubuk larangan tersebut baik disadari dan dipahami atau tidak merupakan sikap pelestarian lingkungan perairan sungai (Supriatna, 2013).

Perairan Sungai Batang Jujuhan merupakan salah satu sungai utama di Kabupaten Bungo dan merupakan bentuk perairan yang terbuka dan bermuara di sungai Batang Hari. Hasil obsevasi dilapangan bahwa bagi masyarakat petani nelayan sungai dimanfaatkan untuk usaha penangkapan ikan, budidaya ikan dan sebagian masyarakat digunakan untuk mandi.

Adapun tujuan penelitian ini adalah untuk mengetahui bagaimana bentuk pengelolaan lubuk larangan sebagai bentuk kearifan lokal di Sungai Batang Jujuhan Kabupaten Bungo. Berdasarkan kajian tentang Konservasi
ojs.umb-bungo.ac.id/index-php/SEMAHJPSP ISSN : 2580-0736

dan sungai yang ada di Kabupaten Bungo dimana telah banyak ditemui lubuk larangan di daerah Sungai Batang Jujuhan, dan belum pernah diadakan penelitian sebelumnya. Sehubungan dengan hal di atas maka perlu dilakukan kajian ilmiah atau penelitian tentang Pengelolaan Lubuk Larangan Sebagai Bentuk Kearrifan Lokal di Sungai Batang Jujuhan Kabupaten Bungo.

\section{METODE PENELITIAN}

Penelitian ini dilaksanakan pada bulan September 2017 s/d Februari 2018. Bertempat di Kecamatan Jujuhan dan Jujuhan Ilir Kabupaten Bungo. alat yang digunakan dalam penelitian ini yaitu alat tulis, kamera, buku panduan wawancara, peta lokasi penelitian. Dalam penelitian ini materi yang digunakan yaitu mendesktiptifkan system pengelolaan lubuk larangan serta wawancara mengenai responden masyarakat tentang sistem pengelolaan lubuk larangan di Sungai Batang Jujuhan Kabupaten Bungo.

Penelitian ini bersifat deskriptif kualitatif dan eksperimen. deskriptif kualitatif yaitu untuk memberikan gambaran dan penjelasan secara faktual dan akurat mengenai fakta - fakta dan gejala yang ada di lokasi penelitian, sedangkan 
SEMAH : Journal Pengelolaan Sumberdaya Perairan VOL. 3 No. 1

April 2019

eksperimen, yaitu melakukan survei, pengambilan data dan pengamatan langsung di lapangan dengan menggunakan data kuisioner atau wawancara langsung dengan responden. Sedangkan data sekunder meliputi inventarisasi kondisi sosial, ekonomi, lingkungan dan budaya masyarakat di kawasan lubuk larangan

Data yang digunakan dalam penelitian ini adalah data primer yaitu data dari hasil survei dan pengamatan langsung di lokasi penelitian, dan hasil wawancara langsung dengan responden, sedangkan data sekunder, yaitu data yang di kumpulkan dari pihak-pihak terkait/ stakeholder yang berasal dari masyarakat/ nelayan, tokoh masyarakat lokal, perangkat dusun, serta pengelola lubuk larangan.

Metode yang digunakan untuk penentuan lokasi penelitian adalah dengan purposive sampling, sedangkan metode untuk mengumpulkan data dan untuk mendapatkan data primer dengan mengunakan: wawancara langsung, dan observasi Langsung dengan mencatat kegiatan yang dilakukan oleh masyarakat yang terlibat dalam pengelolaan lubuk larangan .

Penelitian ini terbatas untuk mengetahui Sistem Pengelolaan Lubuk Larangan sebagai salah satu bentuk
ojs.umb-bungo.ac.id/index-php/SEMAHJPSP

ISSN : 2580-0736

kearifan lokal yang meliputi: proses Perencanaan, pengorganisasian, pelaksanaan, pengawasasn dan sanki-sanksi.

Analisa yang digunakan dalam penelitian ini adalah berupa analisa deskriptif kualitatif, artinya data yang dikumpulkan diolah selanjutnya dibahas guna menggambarkan keadaan yang sebenarnya agar mudah dipahami. Analisa data dilakukan sejak peneliti di lapangan, sewaktu pengumpulan data dan setelah semua data terkumpul atau setelah penelitian selesai.

\section{HASIL DAN PEMBAHASAN}

\section{Pengelolaan Lubuk Larangan di Sungai Batang Jujuhan}

Dusun Rantau Panjang terdapat lubuk larangan Hugo, di Dusun Pulau Batu terdapat lubuk larangan yang dinamakan Pulau Batu dan di Dusun Aur Gading terdapat lubuk larangan Beringin Jaya. Berdasarkan hasil penelitian yang telah dilakukan tentang pengelolaan lubuk larangan adalah sebagai berikut:

\section{a. Lubuk Larangan Hugo}

1) Perencanaan Lubuk Larangan Hugo Berdasarkan hasil penelitian yang telah dilakukan di Dusun Rantau Panjang di lubuk larangan Hugo bahwa muncul ide 
SEMAH : Journal Pengelolaan Sumberdaya Perairan VOL. 3 No. 1

April 2019

untuk membuat lubuk larangan ini, dilatar belakangi dari Dusun Rantau Ikil yang mendapat jatah benih ikan dari Dinas Perikanan Jambi. Bertitik tolak dari ide atau gagasan pembentukan lubuk larangan, kemudian hal ini disampaikan kepada pemerintahan Dusun Rantau Panjang, dalam rangka upaya untuk melestarikan ikan - ikan yang ada di Sungai Batang Jujuhan. Tindak lanjut dari hal ini diadakanlah musyawarah bersama dengan masyarakat dusun Rantau Panjang, untuk menentukan lokasi yang tepat untuk lubuk larangan dan waktu yang tepat dalam pembentukanya. Dari hasil musyawarah bersama maka terbetuklah lubuk larangan yang diberi nama dengan " HUGO " di Sungai Batang Jujuhan.

2) Pengorganisasian Lubuk Larangan
Hugo

Berdasarkan hasil penelitian yang telah dilakukan di Dusun Rantau Panjang, bahwa dalam rapat atau musyawarah dusun demi kelancaran pelaksanaan lubuk larangan Hugo ini dibentuklah organisasi yang bernama " Kelompok Masyarakat Pengawas yang singkat dengan nama POKMASWAS. "

Tujuan untuk menentukan jangka waktu panen, sistem panen dan pengawasannya. POKMASWAS merupa-
ojs.umb-bungo.ac.id/index-php/SEMAHJPSP

ISSN : 2580-0736

kan sebuah lembaga/organisasi yang dibentuk untuk mengawasi jalannya lubuk larangan sehingga pelaksanaannya dapat berjalan dengan lancar.

\section{3) Pelaksanaan Lubuk Larangan Hugo}

Berdasarkan hasil dari rapat/ musyawarah yang dilakukan oleh perangkat dusun dan masyarakat Rantau panjang maka terlaksanalah pembentukan lubuk larangan di Dusun Rantau Panjang . Lubuk larangan ini terbentuk pada tanggal 21 Agustus 2014 jam 2 siang. Setelah membaca surat yasin. Acara dilanjutkan dengan pembacaan Do'a untuk memohon keselamatan dan kesejahteraan penduduk kepada Allah SWT, agar diberikan kemudahan dan kelancaran dalam pelaksanaan lubuk larangan.

Adapun sanksi yang berlaku bagi lubuk larangan Hugo kalau ada yang melanggar atau menangkap ikan di lubuk larangan Hugo akan diberi teguran.

$$
\text { Menurut Abdullah }
$$
pelaksanaan adalah suatu proses rangkaian kegiatan tindak lanjut setelah program atau kebijaksanaan ditetapkan yang terdiri atas pengambilan keputusan, langkah yang strategis maupun operasional atau kebijaksanaan menjadi kenyataan guna 
SEMAH : Journal Pengelolaan Sumberdaya Perairan VOL. 3 No. 1

April 2019

mencapai sasaran program yang ditetapkan semula.

\section{4) Pengawasan Lubuk Larangan Hugo}

Sistem pengawasan lubuk larangan Hugo ini dibicarakan dalam musyawarah, dalam rangka mengantisipasi terjadinya pelanggaran baik dari dalam masyarakat itu sendiri maupun dari pihak luar.

Tujuan diadakan pengawasan dilubuk larangan agar tidak terjadi penangkapan ikan secara liar sehingga tidak terjadi kepunahan. Menurut Lestari (2012), bahwa keberadaan larangan perlu ada monitoring / pengawasan yang bertujuan untuk memantau orang-orang yang tidak bertanggung jawab yaitu mengambil ikan sebelum waktu yang ditentukan.

\section{b. Lubuk Larangan Pulau Batu}

1. Perencanaan Lubuk Larangan Pulau Batu

Berawal dari adanya ide Datuk Rio, ninik mamak, alim ulama, tokoh adat, ketua pemuda dan masyarakat setempat. Maka disampaikanlah ke pemerintahan Dusun Pulau Batu untuk segera diadakan musyawarah, mengingat banyak terjadi pendompengan, penangkapan ikan secara liar. Dengan adanya musyawarah ini maka perangkat dusun beserta masyarakatnya
ojs.umb-bungo.ac.id/index-php/SEMAHJPSP

ISSN : 2580-0736

dapat mentukan lokasi yang pantas serta kondisi yang pas untuk pembuatan lubuk larangan.

Dari hasil musyawarah bersama di Dusun Pulau Batu ini dibentuk lubuk larangan yang diberi nama sesuai dengan nama dusunnya yaitu " Pulau Batu." Pembentukan lubuk larangan Pulau Batu bertujuan untuk melestarikan ikan - ikan yang berada disungai, untuk menambah kas dusun serta menghindari adanya penangkapan ikan secara liar. Dengan musyawarah masyarakat beserta perangkat dusun dapat menetukan kapan waktu yang tepat pembentukannya dan penentuan lokasi lubuk larangan.

Hal ini sesuai dengan pendapat Parwati, dkk (2012), menyatakan bahwa perencanaan lubuk larangan Ngalau Agung pada dasarnya diprakasai oleh tokoh pemuda yang tergabung dalam kelompok pemuda kampung surau yaitu Ikatan Pemuda Pelopor Kampuang Surau (IPPKAS) pada tahun 2004.

Perencanaan pengelolaan lubuk larangan dilaksanakan melalui musyawarah adat dengan melibatkan seluruh anggota masyarakat. Adapun hal-hal yang dibahas dalam merencanakan pengelolaan lubuk larangan adalah : 1) Merumuskan tujuan pengelolaan lubuk larangan, 
SEMAH : Journal Pengelolaan Sumberdaya Perairan VOL. 3 No. 1

April 2019

memperbaiki strategi dan aturan-aturan dalam sistem pengelolaan lubuk larangan, dan 3) Rencana pengembangan aktivitas kegiatan pengelolaan lubuk larangan, (Veraliza, 2014).

5) Pengorganisasian Lubuk Larangan Pulau Batu

Demi kelancaran pelaksanaan lubuk larangan Pulau Batu diadakanlah musyawarah untuk membentuk panitia yang akan mengurus dan mengawasi jalannya lubuk larangan ini. Panitia yang telah terbentuk dalam melaksanakan tugasnya harus bermusyawarah dengan masyarakat, untuk menentukan kapan waktu panen, sistem panen dan pengawasannya. Dari hasil musyawarah ini terbentuklah Kelompok Masyarakat Pengawas (POKMASWAS), yang terstruktur dan mempunyai tugas dan tangggung jawab yang berbeda.

Pada tahun 2007 aturan adat lubuk larangan Indarung telah dikukuhkan dalam surat keputusan ninik mamak secara tertulis, keputusan adat tersebut dikeluarkan dengan pertimbangan demi menjaga kelestarian sumber daya ikan, Kabupaten kuantan singingi dalam wilayah Desa Pangkalan Indarung (Veraliza, 2014).

6) Pelaksanaan Lubuk larangan Pulau Batu
ojs.umb-bungo.ac.id/index-php/SEMAHJPSP

ISSN : 2580-0736

Berdasarkan hasil penelitian yang telah dilakukan di lubuk larangan Pulau Batu maka terlaksanalah pembentukan lubuk larangan ini pada bulan Juni 2014

Hal ini disampaikan oleh tokohtokoh adat bahwa dalam lubuk larangan Pulau Batu ini tidak ada sanksi mengingat masyarakat sudah merasa takut duluan. Acara dilanjutkan dengan pembacaan Do’a yang berisikan keselamatan dan kesejahteraan kepada sang kholik, memohon agar pembentukan lubuk larangan ini sampai panennya dapat berjalan lancar. Setelah selesai semuanya maka lubuk larangan ini ditutup dan tidak boleh lagi melakukan penangkapan ikan sampai waktu yang ditentukan kemudian diumumkan kepada masyarakat dusun dan dusun tetangga bahwa sungai itu telah menjadi lubuk larangan. Sampai ini belum pernah dilakukan pemanenan ikan pada lubuk larangan pulau batu, mengingat kondisi air yang tidak pernah surut.

Aturan-aturan dalam lubuk larangan pulau batu ini sewaktu panen ikan yaitu penangkapan ikan didalam lubuk larangan tidak diperkenankan untuk memakai alat yang bersifat memusnahkan ikan seperti memakai putas, tuba, atau yang bersifat racun bagi ikan. Ada berbagai jenis alat tangkap yang diperbolehkan seperti lukah, 
SEMAH : Journal Pengelolaan Sumberdaya Perairan VOL. 3 No. 1

April 2019

(bubu), jala, pancing dan jaring, dll. Dan untuk Dusun Pulau Batu selain memakai alat yang diatas rencananya akan memakai alat panen ikan yang disebut dengan takalak unak (Terbuat dari rotan).

Penetapan dilakukan melalui musyawarah kemudian dilanjutkan dengan proses selanjutnya berupa pembacaan Surat Yasin sebanyak 125 kali oleh 40 orang di Masjid Darul Jadid Muhammadiyah Kampung Surau. Acara kemudian dilanjutkan dengan ritual yaitu penanaman sesuatu oleh pawang di lokasi bagian darat yang dianggap batas dan penaburan garam ke air. Penetapa lubuk larangan Ngalau Agung pada awalnya ditentang masyarakat yang bekerja sebagai pencari ikan karena mereka kawatir bahwa dengan penetapan lubuk larangan Ngalau Agung akan melibatkan berpindahnya ikan di seluruh Sungai Batang Pangian ke lokasi lubuk larangan Ngalau Agung sehingga mereka tidak dapat lagi memperoleh ikan, dan akan merugikan secara ekonomis Penelitian Parwati (2012).

Dalam penelitian Diana sari (2016), panen dilakukan melalui musyawarah pengurus dan lembaga adat untuk menentukan waktu dan peralatan yang perlu dipersiapkan. Peralatan yang digunakan untuk menangkap ikan
ojs.umb-bungo.ac.id/index-php/SEMAHJPSP

ISSN : 2580-0736

ditentukan oleh pengurus dan lembaga adat, dengan tujuan tidak merusak atau membunuh seluruh ikan yang ada di lubuk larangan tersebut. Alat yang digunakan umumnya berupa peralatan sederhana dan dapat dibuat sendiri oleh masyarakat setempat seperti jala, lukah, panah ikan dengan cara menyelam.

7) Pengawasan Lubuk Larangan Pulau Batu

Sistem pengawasan lubuk larangan Pulau Batu ini terlebih dahulu dibicarakan saat musyawarah pembentukan lubuk larangan Pulau Batu, yang diadakan dalam mesjid. Setiap orang baik, masyarakat dusun Pulau Batu maupun masyarakat luar dusun berhak mengakses sumberdaya sungai untuk berbagai kepetinggan dengan menggunakan perahu atau berenang disepanjang sungai tersebut. Asalkan tidak mengambil ikan diarea lubuk larangan. Pengelolaan pengawasan terhadap lubuk larangan Pulau Batu ini diserahkan sepenuhnya kepada POKMASWAS yang beranggotakan setiap unsur masyarakat yaitu, Rio, para ninik mamak, tokoh adat, tokoh agama dan pemuda.

Hal senada juga dipertegas Siagian (1990), menyebutkan bahwa yang dimaksud dengan pengawasan adalah 
SEMAH : Journal Pengelolaan Sumberdaya Perairan VOL. 3 No. 1

April 2019

proses pengamatan dari pada pelaksanaan seluruh kegiatan organisasi untuk menjamin agar supaya semua pekerjaan yang sedang dilakukan berjalan sesuai dengan rencana yang telah ditentukan sebelumnya.

\section{c. Lubuk Larangan Beringin Jaya}

1. Perencanaan Lubuk Larangan Beringin Jaya

Berdasarkan hasil penelitian di Dusun Aur Gading bahwa pembentukan lubuk larangan Beringin Jaya ini dimulai dari adanya ide setelah melihat terbentuknya lubuk larangan Hugo di Dusun Rantau Panjang.

Berawal dari adanya ide dari Rio, tokoh adat, tokoh pemuda, ninik mamak dan masyarakat Aur Gading. Setelah melihat kerusakan perairan sungai serta semakin berkurangnya ikan - ikan di Sungai Batang Jujuhan maka diadakanlah musyawarah untuk membangun lubuk larangan ini. Hasil musyawarah ini berupa pemberian nama Lubuk Larangan yaitu " Beringin Jaya."

Hal ini sesuai dengan pendapat Abdulrachman (2010), yang Menyatakan bahwa Perencanaan adalah upaya menyusun keputusan yang bersifat pokok yang dipandang paling penting dan yang
ojs.umb-bungo.ac.id/index-php/SEMAHJPSP

ISSN : 2580-0736

akan dilaksanakan menurut urutannya guna mencapai tujuan yang telah ditetapkan.

a) Pengorganisasian Lubuk Larangan Beringin Jaya

Berdasarkan hasil penelitian yang dilakukan di Lubuk Larangan Beringin Jaya Dusun Aur Gading, ternyata belum terbentuknya POKMASWAS. Untuk sistem pengawasan lubuk larangan dilimpahkan kepada seluruh warga Dusun Aur Gading, sehingga setiap warga mempunyai hak dan kewajiban yang sama dalam mengelola lubuk larangannya.

Menurut Lubis (2010), hukum adat ditentukan oleh kesepakatan bersama atau pun dari hasil musyawarah masyarakat terhadap aturan yang akan dibuat untuk kepentingan suatu daerah tertentu. Sesuatu dengan keyakinan yang ada pada suatu daerah tertentu.

b) Pelaksanaan Lubuk Larangan Beringin Jaya

Berdasarkan hasil penelitian yang telah dilakukan di Dusun Aur Gading di Lubuk Larangan Beringin Jaya. Maka terbentuklah lubuk larangan ini pada tahun 2016. Pembacaan Do’a dipimpin oleh tokoh agama yang bertujuan untuk memohon kepada Allah SWT, agar lubuk larangan ini 
SEMAH : Journal Pengelolaan Sumberdaya Perairan VOL. 3 No. 1

April 2019

dapat berjalan dengan baik dan lancar serta diridhoi oleh Allah SWT. Kegiatan diawali dengan pembacaan surat yasin sebanyak 1 kali yang dibacakan oleh Rio Bapak Hamrozi dan diikuti oleh semua peserta yang hadir, setelah pembacaan surat yasin selesai, maka diteruskan dengan pembacaan sumpah yang berisikan " Barang siapa yang menngambil ikan dilubuk larangan Beringin jaya perutnya akan gembung, terus pusing-pusing dan akhirnya meninggal secara perlahan-lahan. Terakhir acara ditutup dengan pembacaan." Do'a yang dipimpin oleh tokoh agama yang betujuan untuk memohon kepada Allah SWT, agar lubuk larangan ini dapat berjalan dengan baik dan lancar serta diridhoi oleh Allah SWT.
c) Pengawasan Lubuk Larangan Beringin Jaya

Berdasarkan hasil penelitian yang telah dilakukan di Dusun Aur Gading di Lubuk Larangan Beringin Jaya bahwa pengawasan di limpahkan kepada seluruh masyarakat setempat.

Sistem pengawasan yang akan dilakukan pada lubuk larangan Beringin Jaya bahwa hasil musyawarah : Semua lapisan masyarakat Dusun Aur Gading akan terlibat langsung dalam hal
ojs.umb-bungo.ac.id/index-php/SEMAHJPSP

ISSN : 2580-0736

melakukan pengawasan. Pengawasan bukan saja dilakukan terhadap pihak yang bermaksud mencuri ikan, tetapi juga terhadap pengguna alat - alat panen.

Dalam hal ini dapat disimpulkan karena lubuk larangan ini dibuat atas kesepakatan bersama maka hak pengawasan sepenuhnya menjadi tanggung jawab bersama. Untuk mengantisipasi pelanggaran yang akan terjadi maka dibuatlah sanksi yang berbunyi "Siapa yang mengambil ikan dilubuk larangan Beringin Jaya Perut membesar, pusing - pusing dan mati secara perlahan-lahan." Sehingga sampai saat ini belum terjadi pelanggaran terhadap lubuk larangan Beringin Jaya.

\section{KESIMPULAN DAN SARAN}

1. Kesimpulan

Dari hasil penelitian menyatakan bahwa bentuk - bentuk kearifan lokal masyarakat Dusun Rantau Panjang, Dusun Pulau Batu dan Aur Gading dalam upaya mengelola lubuk larangan Hugo, Pulau Batu dan lubuk larangan Beringin Jaya adalah : 1) Merencanakan pembentukan lubuk larangan melalui musyawarah dalam upaya menyelamatkan lingkungan perairan sungai, 2) Terbentunknya aturan - aturan dan sanksi bagi lubuk larangan Hugo dan aturan - aturan saja tidak ada sanksi bagi lubuk larangan Pulau Batu dan Beringin 
SEMAH : Journal Pengelolaan Sumberdaya Perairan VOL. 3 No. 1

April 2019

Jaya, 3) Masyarakat Dusun Rantau Panjang, Dusun Pulau Batu dan Beringin Jaya mempunyai kepercayaan bahwa yang mengambil ikan dilubuk larangan akan meninggal, 4) Dapat mengubah prilaku masyarakat kearah yang lebih posistif dari aspek ekologi dan sosial, seperti : Mengunakan alat panen yang ramah lingkungan seperti lukah, jala, jaring, Melarang menangkap ikan di sepanjang lubuk larangan , Memelihara dan memanfaatkan lubuk sebagai tempat berkembangbiaknya ikan - ikan

2. Saran

Berdasarkan hasil penelitian perlu dilakukan penelitian lebih lanjut mengenai :

1) Diharapkan adanya penelitian lanjutan tentang bentuk-bentuk kearifan lokal dalam pemanenan ikan lubuk larangan untuk Dusun Rantau Panjang, Pulau Batu dan Aur gading

2) Diharapkan adanya peran serta dan dukungan dari pemerintah dusun dalam hal ini peningkatan sumberdaya manusia dalam pelatihan bagi pengurus kelompok pengawas masyarakat (POKMASWAS),

3) Kerarifan lokal lubuk larangan di Dusun Rantau panjang, Pulau Batu, Aur Gading sebagai wujud atas partisipasi dan kesadaran yang tinggi
ojs.umb-bungo.ac.id/index-php/SEMAHJPSP

ISSN : 2580-0736

dari masyarakat agar terus dijaga dan dilindungi

\section{DAFTAR PUSTAKA}

Abdullah Syukur, 1987. Kumpulan Makalah "Studi Implementasi Latar Belakang Konsep Pende-katan dan Relevansinya Dalam Pembangunan," Persadi Ujung Pandang.

Atmosudirjo, Prajudi. 1979. Adiministrasi dan Manajemen Umum PT. Gahlia

Bintoro Tjokroamidjoyo, 1980. Pengantar Administrasi Pembangunan LP3ES. Jakarta.

Budiyono, 2012. Pengelolaan Lubuk Larangan Sebagai Bentuk Kerarifan Lokal

Dinas Peternakan dan Perikanan 2009. Laporan Operasi Lintas Sektoral, Muara Bungo, Jambi.

Dinas Peternakan dan Perikanan, 2010. Evaluasi dan laporan Muara Bungo Jambi.

FAO, 2003. Ecosystem Approach to Fisheries, FAO Technical Paper.

Kaufman,Roger A.(1972), Educational system Planning, Now Jersey: Prentice Hall, Inc.

Lestari, Fajar Surya Paus Iskarni, Yudi Antoni, 2012, Lubuk Ikan Larangan Sebagai Bentuk Kearifan Lokal di Kampung Kota Kandis Kecamatan Lengayang Kabupaten Pesisir selatan.

Parwarti, Amin.2012. Pelestarian Lingkungan Melalui Kearifan local 
SEMAH : Journal Pengelolaan Sumberdaya Perairan VOL. 3 No. 1

April 2019

Lubuk Larangan Ngalau Agung, (Studi di Kampung Surau Nagari Gunung Kecamatan Pulau Punjung Kabupaten Dharmasraya Provinsi(Sumatera Barat)

Parwati, Amin Purnaweni, Hartati, Dwi Anggoro, Didi. 2012 Nilai Pelestarian Lingkungan dalam Kaearifan Lokal Lubuk Larangan Ngalau Agung di Kampung Surau Kabupaten Dhamasraya Provinsi SunateraBarat. Prosiding Seminar Nasional Pengelolaan Sumberdaya Alam dan Lingkungan

Semarang.

Putra, Erwin, 2001 Lubuk Larangan Sebagai Organisasi Masyarakat di Tinjau dari Aspek Sosial Ekonomi dan Aspek Lingkungan, Studi Kasus di Kab. Mandailing Natal Sumbar.

Santoso, Singgih, 2012. Statistik Parametrik. Jakarta : PT. Gramedia Pustaka Umum.

Seru jambi, Com. Produksi Lubuk larangan Dharmasraya 201,8 Ton.

Siagian, Sondang. 1990. Administrasi Pembangunan Jakarta : Gunung Agung.

Siswandi, 2010. Kearifan Lokal Dalam Melestarikan Air ( Studi Kasus di Desa Purwaganda Kecamatan Boja, Kabupaten Kendal ).

Suhartini, 2009. Kajian Kearifan Lokal Masyarakat Dalam Pengelolaan Sumber Daya alam dan lingkungan (Jurnal) 